\title{
The indirect effect of servant leadership on employee attitudes through diversity climate in selected South African organisations
}

\begin{tabular}{|c|c|}
\hline \multicolumn{2}{|c|}{$\begin{array}{l}\text { Authors: } \\
\text { Sean McCallaghan }{ }^{1} \\
\text { Leon Jackson }{ }^{2} \\
\text { Marita Heyns }\end{array}$} \\
\hline \multicolumn{2}{|c|}{ Affiliations: } \\
\hline \multicolumn{2}{|c|}{$\begin{array}{l}\text { Area, North-West University, } \\
\text { Vanderbijlpark, South Africa }\end{array}$} \\
\hline \multicolumn{2}{|c|}{$\begin{array}{l}{ }^{2} \text { WorkWell Research Unit, } \\
\text { Business School, North-West } \\
\text { University, Potchefstroom, } \\
\text { South Africa }\end{array}$} \\
\hline \multicolumn{2}{|c|}{$\begin{array}{l}\text { Research Project Registration: } \\
\text { Project Number: } \\
\text { EMSPBS09/09/16-01/01 }\end{array}$} \\
\hline \multicolumn{2}{|c|}{$\begin{array}{l}\text { Corresponding author: } \\
\text { Sean McCallaghan, } \\
\text { sean.mccallaghan@nwu.ac.za }\end{array}$} \\
\hline \multicolumn{2}{|c|}{$\begin{array}{l}\text { Dates: } \\
\text { Received: } 04 \text { Nov. } 2019 \\
\text { Accepted: } 14 \text { Mar. } 2020 \\
\text { Published: } 11 \text { June } 2020\end{array}$} \\
\hline \multicolumn{2}{|c|}{$\begin{array}{l}\text { How to cite this article: } \\
\text { McCallaghan, S., Jackson, L., \& } \\
\text { Heyns, M. (2020). The indirect } \\
\text { effect of servant leadership on } \\
\text { employee attitudes through } \\
\text { diversity climate in selected } \\
\text { South African organisations. SA } \\
\text { Journal of Human Resource } \\
\text { Management/SA Tydskrif vir } \\
\text { Menslikehulpbronbestuur, } \\
\text { 18(0), a1297. https://doi. } \\
\text { org/10.4102/sajhrm. } \\
\text { v18i0.1297 }\end{array}$} \\
\hline \multicolumn{2}{|c|}{$\begin{array}{l}\text { Copyright: } \\
\text { (c) 2020. The Authors. } \\
\text { Licensee: AOSIS. This } \\
\text { is licensed under the } \\
\text { Creative Commons } \\
\text { Attribution License. }\end{array}$} \\
\hline \multicolumn{2}{|l|}{ Read online: } \\
\hline 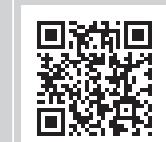 & $\begin{array}{l}\text { Scan this QR } \\
\text { code with your } \\
\text { smart phone or } \\
\text { mobile device } \\
\text { to read online. }\end{array}$ \\
\hline
\end{tabular}

Orientation: Organisations are continuously diversifying their workforces and require information on how to benefit from positive diversity-related outputs. Servant leadership might provide a solution to improve diversity-related outputs. Literature proposes that servant leadership, diversity climate and employee outputs are related; yet, literature is silent on how these observations would operate in a transitional environment where organisations are intentionally attempting to correct inherited workforce imbalances.

Research purpose: The study examined indirect effects of diversity climate on the relationship between servant leadership and employee attitudes.

Motivation for the study: Examinations of the indirect effects of diversity climate are limited.

Method: A quantitative approach with cross-sectional design collected 230 responses from a convenience sample. Respondents completed assessments for servant leadership, diversity climate, organisational commitment, job satisfaction and intention to quit. Statistical analysis included descriptive statistics, correlational analysis and three independent mediation models.

Main findings: Servant leadership and diversity climate are positively associated with organisational commitment, job satisfaction, and non-intention to quit. Servant leadership demonstrated a direct effect on diversity climate, organisational commitment, job satisfaction and non-intention to quit. Diversity climate had a positive impact on organisational commitment. Servant leadership demonstrated an indirect effect on organisational commitment via diversity climate.

Practical implications: The improvement of organisational commitment cannot only rely on servant leadership; a conducive diversity climate is also required.

Contribution and value-added: The examination contributes towards limited diversity climate research with evidence of the indirect capacity of diversity climate.

Keywords: Diversity climate; intention to quit; job satisfaction; organisational commitment; servant leadership.

\section{Introduction and background}

Our societies are becoming more diverse. An increasing number of organisations are moving away from merely managing diversity because of legal obligations. In the current context of organisations, diversity is an integral part of co-operative management and planning, which is actively supported (Anand \& Winters, 2008). Positive consequences for organisations embracing and strategically managing diversity can include several organisational and employee benefits (Joubert, 2017). Employees who indicated that they are receptive towards diversity and especially the effective management of diversity are more inclined to also consider their organisation's overall performance as positive. The associated advantages of a more diverse workforce include increased sales performance (Richard, Stewart, McKay, \& Sacket, 2017), organisational commitment and job satisfaction (Hicks-Clarke \& Iles, 2000). Diversity further attracts the attention of organisations as it has been proven that more diverse organisations have distinct competitive advantages over heterogeneous organisations (Sü $\beta$ \& Kleiner, 2007). In addition, diversified organisations also have access to a larger and improved quality pool of human talent because of an increase in supply from future employees (Foster \& Harris, 2005). 
While the constructive benefits of a diverse organisation are noticeable, the negative consequences are also a reality. Such negative consequences include counterproductive effects (Joshi \& Roh, 2009; Van Dijk, Van Engen, \& Van Knippenberg, 2012); dissatisfaction and conflict (Jayne \& Dipboye, 2004) as well as subtle discrimination (Ogbanna \& Harris, 2006). In the context of this research, the focus is on constructive and positive outcomes of diversity. This study contributes towards developing solutions, rather than reconfirming the opposite effects. The possible solution to perhaps gain full benefits associated with diversity and minimising the recorded negative associations might be found in leadership.

Leadership, especially servant leadership, plays an essential role in augmenting diversity outcomes, 'especially in supporting a climate respectful of differences, as well as affirming the fundamental worthiness of diverse employees' (Gotsis \& Grimani, 2016, p. 1002). Servant leadership is a developing area that is linked to ethics, virtues and morality (Parris \& Peachy, 2013). It is also a form of leadership that articulates emotional, relational and moral dimensions of management very well (Reed, Cohen, \& Colwell, 2011). It is also about influence, caring, listening, creating a climate of love, simplicity and consciousness, as well as contributing towards a stronger sense of interactional justice, optimistic attitude and commitment to change (Choudhary, Akhtar, \& Zaheer, 2013; Kool \& Van Dierendonck, 2012).

There is enough evidence to indicate that servant leadership improves individual and team-level effectiveness ( $\mathrm{Hu} \&$ Liden, 2011). Carter and Baghurst (2014) state that servant leadership has the potential to improve employee engagement, whilst Liden, Wayne, Zhao and Henderson (2008) confirm the relationship between servant leadership and organisational commitment. From a perspective of well-being - reducing burnout and turnover intentions Hunter et al. (2013) explained that servant leadership has a positive influence on individuals. Chan and Mak (2014, p. 280) found evidence to indicate that servant leadership behaviour is strongly and positively associated with subordinates' trust in leader and job satisfaction - only for short-tenure subordinates - 'implying that managers should differentiate leader tactics accordingly'.

While the associated benefits of diversification are appealing to organisations, the landscape of diversity has also drawn the attention of researchers. Because of globalisation and increasing workforce diversification, a heightened increase is noted for research on diversity tailored to develop new, improved approaches to diversity management practices and interventions. The study of diversity climate is also considered one of the new areas that researchers are starting to focus on in the world of diversity literature (Pugh, Dietz, Brief \& Wiley, 2008). Diversity climate entails how employees appreciate and form impressions of or perceptions on how well the organisation is performing on the diversity front.
This relates to specific perspectives on organisational diversity policies and practices (Pugh et al., 2008).

Taking into consideration the independent associations between servant leadership, diversity climate and employee attitudes, and the fact that leadership is regarded as an important aspect to enhance the benefits of diversity (Wieland, 2004), the present study aims to answer the question regarding whether or not diversity climate has an indirect effect on the relationship between servant leadership and the selected employee attitudes. The intended model is depicted in Figure 1.

\section{Research objectives}

The primary objective of this study is to investigate the indirect effect of leadership on employee attitudes through a diversity climate. The secondary objectives include the following:

- Examine the relationships between servant leadership, diversity climate and the selected employee attitudes (organisational commitment, intention to quit and job satisfaction)

- Investigate the direct effect of servant leadership on diversity climate

- Investigate the direct effect of diversity climate on employee attitudes

- Explore the direct effect of servant leadership on employee attitudes.

The following section is dedicated to previous literature findings on the variables under investigation as proposed in the model in Figure 1.

\section{Literature review}

\section{Proposed model antecedent: Servant leadership}

Originally proposed by Greenleaf (1977), servant leadership, in principle, is a service to followers. Servant leaders are also motivated by something more important than the need for power, namely, the need to serve and, therefore, servant

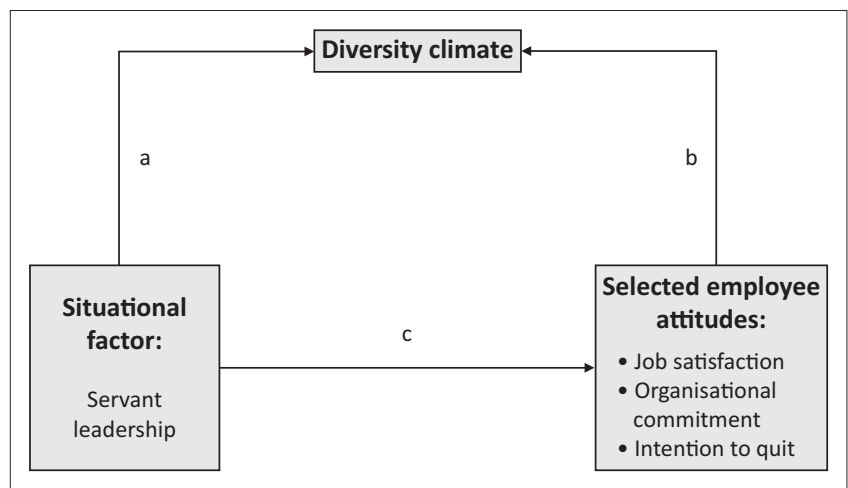

FIGURE 1: Servant leadership as a model antecedent, diversity climate as a mediator and employee attitudes as model outcome. 
leaders would go beyond self-interest in leading others (Luthans \& Avolio, 2003).

According to Hale and Fields (2007), servant leadership is:

$[A] n$ understanding and practice of leadership that places the good of those led over the self-interest of the leader, emphasizing leader behaviours that focus on follower development, and de-emphasizing glorification of the leader. (p. 397)

Servant leadership further emphasises moral behaviour, protecting followers from leaders who act for self-gain or out of selfishness (Liden et al., 2008). Servant leaders also exhibit the ability to recognise their moral responsibility towards the success of the organisation (and the success of their subordinates), the organisation's clients and any other interested party (Ehrhart, 2004). According to Reed et al. (2011), servant leaders would typically display behaviours of interpersonal support, building community, altruism, egalitarianism and moral integrity. A recent South African study also found similar characteristics of servant leadership from an extend literature review. These characteristics include 'authenticity, humility, integrity, listening, compassion, accountability, courage, and altruism' (Coetzer, Bussin, \& Geldenhuys, 2017, p. 19). Although servant leadership demonstrates several similarities with other leadership styles, it offers a more distinctive influence on organisational stakeholders (Choudhary et al., 2013).

\section{Proposed mediator: Diversity climate}

The composition of the modern workforce has changed considerably over recent years and has stimulated interest in shared diversity perceptions, known as diversity climate (Pugh et al., 2008). According to Mor Barak, Cherin and Berkman (1998), individuals form perceptions about the stance of an organisation's diversity as well as their own stance of diversity. Mor Barak et al. (1998, p. 83) further define diversity climate as 'employee behaviours and attitudes that are grounded in perceptions of the organisational context related to women and minorities'. Although Mor Barak et al.'s (1998) definition is still relevant, recent literature has extended the conceptualisation of diversity climate to include multicultural perspectives, in other words, situations where cultural security, cultural diversity and cultural equity are embodied and promoted (Ojukwu \& Oni, 2017). It is especially Hofhuis, Pernill, Van der Rijt and Vlug's (2016) view on the diversity climate that clearly conceptualises these inter-related diversity disciplines. Hofhuis et al. (2016) illustrate diversity climate as an environment characterised by situations where employees can freely discuss their cultural heritage and display cultural behaviours. This conceptualisation also relates to environments where diversity is actively promoted with a belief that cultural differences provide value to the team or organisation (Hofhuis et al., 2016).

While the focus on a constructive diversity climate should be emphasised for this particular study, it cannot ignore the benefit associated with an accurate assessment of an organisation's diversity climate. The end result for organisations wishing to manage one of their most valuable resources would largely depend on employees' perceptions of diversity management initiatives (Kaplan, Wiley, \& Maertz, 2011). Employees scrutinise their organisation's diversity-related policies, practices and even work environment, which lead to the formation of perceptions on how well their organisation is doing in terms of valuing diversity (Madera, Dawson, \& Neal, 2013). Organisations that would like to benefit from the positive performance associated with diversity should also take care of how employees perceive their efforts towards supporting and driving diversity initiatives (Mor Barak et al., 1998).

Diversity climate refers to the 'aggregate employee perceptions in terms of the organisation's diversity-related formal structure characteristics and informal values' (Gonzalez \& Denisi, 2009, p. 24). The perceptions employees form regarding whether an organisation is fair towards all groups are essential to the diversity climate and relate to how employees perceive organisational efforts towards inclusion or exclusion of individuals from diverse backgrounds (Mor Barak et al., 1998). The explanation of diversity climate by Hofhuis, Van der Zee and Otten (2012) accurately captures the present study's view on diversity climate. Hofhuis et al. (2012, p. 969) consider diversity climate as the degree to which an organisational climate facilitates the presence of cultural differences, and views this diversity as a positive asset'. The view of Hofhuis et al. (2012) is specifically applicable to South African organisations that employ a wide range of diverse employees, all with different cultural backgrounds.

\section{Proposed model outcome: Employee attitudes}

Although several employee attitudes exist in mainstream research, the current study focuses on organisational commitment, intention to quit and job satisfaction. The selection of these employee attitudes was jointly based on organisational benefits associated with these selected employee attitudes and their proven impact as positive consequences of a constructive diversity climate. During a review study on diversity climate, McKay and Avery (2015) reported that diversity climate was associated with a decrease in turnover intention, improved organisational commitment and job satisfaction.

Organisational commitment refers to an employee's strong belief in the organisation's goals and values. It further entails an employee's 'enthusiasm to demonstrate additional effort on behalf of the organisation, coupled with a wish to remain a member of the specific organisation' (Mowday, Porter, \& Steers, 1982, p. 20). It is well recorded that organisational commitment comprises affective, continuance and normative commitment. Affective commitment contains value similarities between employees and the organisation, and is mostly a result of the compatibility between employee objectives and values, and organisational goals (Suliman \& Iles, 2000). Continuance commitment refers to an employee's continued connection with an organisation because of the perceived high costs and risks involved when leaving an organisation' (Curtis \& Wright, 2001, p. 59), while normative 
commitment refers to 'an employee's feelings of having an obligation to stay with the organisation' (Allen \& Meyer, 1996, p. 2). Employees who demonstrate high levels of organisational commitment have a propensity to remain with the organisation and continue to demonstrate constructive behaviours that result in improved organisational performance (Vandenberghe, Bentein, \& Stinglhamber, 2004). For the purpose of this study, the focus was directed towards affective commitment, as this form of commitment has generated the most interest amongst researchers (Albrecht, Bakker, Gruman, Macey, \& Saks, 2015).

According to Boshoff, Van Wyk, Hoole and Owen (2002), intention to quit is considered as the strength of a person's view that he or she does not want to stay with the current employer, while according to Bothma and Roodt (2012), intention to quit is the realisation of the employee and his or her willingness to purposely leave the organisation. Intention to quit precedes the final step in the withdrawal process (Bothma \& Roodt, 2012). The benefits associated with a reduction in an employee's intention to quit have consistently been associated with both job satisfaction and organisational commitment (Yalabik, Popaitoon, Chowne, \& Rayton, 2013).

Job satisfaction entails how an individual feels about and thinks of his or her job (Colquitt, Lepine, \& Wesson, 2011). It can be classified into two dimensions: intrinsic and extrinsic satisfaction. Intrinsic satisfaction refers to the employee's job content, such as independence, an assortment of skills, supervision and amount of responsibility, while extrinsic satisfaction is related to the work environment and includes incentives, rewards, promotion opportunities, safety and satisfactory working hours (Chatzoglou, Vraimaki, Komsiou, Polychrou, \& Diamantidis, 2011). Job satisfaction has also been associated with organisational performance in the form of total asset turnover, revenue per employee, labour costs per employee and earnings before taxes per employee (Bakotić, 2016). Job satisfaction is, therefore, an important organisational aspect that would require continuous management.

\section{Servant leadership, diversity climate and employee attitudes}

In terms of servant leadership in relation to diversity climate and employee attitudes, Van Dierendonck and Nuijten (2011) established that servant leadership is strongly related to organisational cultures and climates for inclusion. Gotsis and Grimani (2016, p. 985) explained servant leadership as one of the leadership styles that might be of a 'particular interest to the endeavour of nurturing inclusive climates'. Servant leaders will typically motivate and encourage equitable and socially responsible practices, as well as interventions that will decrease tensions between subgroups, which are, in turn, expected to encourage followers' feelings of belongingness (Gotsis \& Grimani, 2016). Not only has servant leadership been established as a worthy contributor towards organisational performance (Leem, 2015), but it has also been associated with lower observations of intention to quit (Brohi, Jantan, Sobia, \& Pathan, 2018), improved organisational commitment (Jang \& Kandampully, 2018) and increased job satisfaction (Cerit, 2009).

According to Gonzalez and Denisi (2009), diversity climate will have an impact on organisational performance in the form of productivity and a return on profit. Consequences of diversity climate have not been restricted to the organisational level. At the employee level, diversity climate has demonstrated an inverse relationship with intention to quit (Gonzalez \& Denisi, 2009) and a positive, direct association with organisational commitment (Gonzalez \& Denisi, 2009; Parks, Knouse, Crepeau, \& McDonald, 2008). Furthermore, diversity climate has demonstrated a direct positive association with job satisfaction (Choi, 2013; Parks et al., 2008). According to Brimhall, Lizano and Mor Barak (2014), diversity climate will have a direct effect on job satisfaction, which in turn will reduce an employee's intention to leave.

According to McKay and Avery (2015), limited studies have explored diversity climate as a mediator. However, from a South African perspective, McCallaghan, Jackson and Heyns (2019a) found evidence to suggest that diversity climate can be considered as a mediator in the relationship between transformational leadership and organisational commitment. According to McCallaghan, Jackson and Heyns (2019b), transformational leadership would also have an indirect effect on job satisfaction via diversity climate.

\section{Problem statement}

The mismanagement of certain South African organisations is currently considered as a large-scale problem and research suggests that agencies combating corruption are not performing well (Budhram \& Geldenhuys, 2018). Because of servant leadership's emphasis on integrity and morality and the fact that South Africa is further attempting to redress inherited imbalances (Jackson, Van de Vijver \& Molokoane, 2013), whilst also combating corruption, this study considers to examine the relationship between servant leadership, diversity climate and employee attitudes as a relevant investigation.

South Africa has a unique history of segregation and historic labour imbalances can still be witnessed. A current labour force report indicates that the South African workforce is still dominated by large groups of men (49\% of total employed population compared to $38 \%$ employment rate of women) and white people $(65 \%$ of total employed population compared to $40.5 \%$ for the African group; $50 \%$ for the mixed race group and 55\% for the Indian or Asian group) (Statistics South Africa, 2018). The dominance of certain demographical groups might pose managerial problems in itself. It might be that this dominance also invites negative organisational observations, especially towards gender and racial discrimination that is still witnessed in South African organisations (Jaga, Arabandi, Bagraim, \& Mdlongwa, 2018). South African researchers have also stated that racial 
stereotypes are still widespread amongst all four South African race groups (African, white, Indian and mixed race) (Durrheim \& Talbot, 2012). These witnessed stereotypes are not restricted to race, but also include gender stereotypes, especially between individuals occupying managerial positions (Booysen \& Nkomo, 2010). Perhaps, effective leadership is what is required in combating these negative associations with diversity.

According to Covey (2006), servant leadership is very applicable to South Africa as this form of leadership displays moral authority, humility, service and sacrifice that can lead to trust and respect. The view of Covey (2006) is supported by Kgatle $(2018$, p. 8), who stated that 'servant leadership is an urgent style for the current state of political leadership in South Africa'. Researchers further indicate that empirical evidence demonstrating the effect of servant leadership on job outcomes is relatively scarce (Chiniara \& Bentein, 2016), together with studies examining variables that could possibly mediate the relationship between servant leadership and employee outcomes (Panaccio, Donia, Saint-Michel, \& Liden, 2015). Chin, Desormeaux and Sawyer (2016) called for a reexamination of leadership theories in diverse settings. To the best of our knowledge, there is no research exploring any relationship between servant leadership and diversity climate and employee attitudes in a South African context. According to McKay and Avery (2015), researchers should test leadership as a non-traditional antecedent of diversity climate and also consider diversity climate as a mediator in possible future studies.

In summary, in order for South African organisations to manage diversity more effectively and to improve negative employee attitudes that might be created by non-conducive diversity climates, relevant and empirically tested evidence is required. As indicated, the South African environment with regard to diversity management is unique and, therefore, South African organisations, managers and leaders would require evidence from a South African investigation. From limited literature it is evident that servant leadership would impact diversity climate, and diversity climate would impact employee attitudes. However, the majority of Western samples were not subjected to the long, legalised segregation and inherited historic labour imbalances as witnessed by South African organisations. Moreover, international diversity climate literature is silent on how servant leadership would impact employee attitudes via diversity climate.

Taking into consideration the preceding paragraphs from the literature review, problem statement and research objectives, the following research questions have been developed:

- What is the type and nature of the relationship between servant leadership, diversity climate and employee attitudes?

- What is the impact of servant leadership on diversity climate?

- What is the effect of diversity climate on employee attitudes?
- What is the impact of servant leadership on employee attitudes?

- What is the indirect effect of servant leadership on employee attitudes through diversity climate?

\section{Study methodology Research design and approach}

This study applied a quantitative approach with a crosssectional design. A cross-sectional design was considered appropriate because it could explain connections amongst variables and serve as the foundation for understanding and theorising occurrences (Spector, 2019). Servant leadership, diversity climate and employee attitudes (organisational commitment, intention to quit and job satisfaction) were assessed at a single point in time and, therefore, the crosssectional design was further considered as appropriate. The anonymous nature of the study ensured that a minimal risk classification was obtained. Questionnaires were only distributed to selected Gauteng-based, South African organisations after permission had been granted via human resource managers, heads of departments or team leaders. Objectives of the study and confidentiality were also communicated to the participants. After a set time, questionnaires were collected from central points at each participating organisation.

\section{Participants and sampling}

Data were primarily collected through a non-probability convenience sample from individuals employed at South Africa-based organisations. Organisations from the manufacturing, financial, retail and industrial sectors were included in the sample. In total, 820 questionnaires were distributed of which 230 responses could be used, resulting in a $28 \%$ response rate. The sample characteristics are presented in Table 1.

\section{Measuring instruments}

The measuring instrument consisted of four main sections. The first section collected biographical data, with the final three sections collecting data relating to observations on servant leadership, diversity climate and employee attitudes, respectively. The measuring instrument comprised the following components.

The biographical section collected authentic data from respondents, including the year of birth, gender, ethnicity, employment status and tenure.

The servant leadership dimension was measured by the Executive Servant Leadership Scale (ESLS) as developed by Reed et al. (2011). The ESLS comprises elements of servant leadership, namely, interpersonal support, building community, altruism, egalitarianism and moral integrity. The ESLS has 55 scale items and uses a five-point Likert scale, ranging from (1) totally disagree to (5) totally agree. A typical item from the ESLS is as follows: 'consider 
TABLE 1: Sample characteristics.

\begin{tabular}{lc}
\hline Biographical element & Percentage \\
\hline Date of birth & 2.0 \\
1945-1950 & 4.4 \\
1951-1960 & 17.4 \\
1961-1970 & 18.4 \\
1971-1980 & 38.1 \\
1981-1990 & 19.7 \\
1990 and onward & \\
Gender & 52.9 \\
Male & 47.1 \\
Female & \\
Qualifications & 17.9 \\
Matric or Grade 12 & 17.5 \\
Post-matric qualification (diploma) & 29.2 \\
University degree (BA, BCom, BSc etc.) & 35.4 \\
Postgraduate degree & \\
Demographic or ethnic group & 69.3 \\
White & 24.9 \\
Black & 2.7 \\
Indian & 1.9 \\
Mixed race & 1.1 \\
Other & \\
Employment status & \\
Permanent & \\
Temporary & 39.6 \\
Level of employment & \\
Senior management & \\
Middle or line management & \\
General worker & \\
\hline AA, Bach.1 & \\
\hline
\end{tabular}

BA, Bachelor of Arts; BCom, Bachelor of Commerce; BSc, Bachelor of Science.

the effects of organisational decisions on the community'. A recent South African application of the ESLS reported the following Cronbach's alpha scores: interpersonal support $(\alpha=0.94)$, building community ( $\alpha=0.85)$, altruism $(\alpha=0.92)$, egalitarianism $(\alpha=0.84)$ and moral integrity ( $\alpha=0.90)$ (Van Heerden, 2015).

The one-dimensional diversity climate was measured with the diversity climate instrument developed by McKay et al. (2007). The instrument (with nine scale items) measures individuals' perceptions regarding the commitment of the organisation towards eliminating discrimination and creating an environment of inclusivity (McKay et al., 2007). The onedimensional diversity climate instrument uses a five-point Likert scale, ranging from (1) well below expectations to (5) well above expectations. A typical item is as follows: 'respect perspectives of people like me'. The original application of the one-dimensional diversity climate instrument recorded a Cronbach's alpha value of 0.91 (McKay et al., 2007).

The job satisfaction dimension was measured by using the short version of the Minnesota Satisfaction Questionnaire (MSQ) (Weis, England, \& Lofquist, 1967). The short version of the MSQ comprises 20 scale items and measures intrinsic, extrinsic and general satisfaction (Weis et al., 1967). The MSQ offers five options for each statement, ranging from (1) very dissatisfied to (5) very satisfied. A typical item from the questionnaire is as follows: 'being able to keep busy all the time'. In terms of reliability for the short version of the MSQ, a South African study reported a Cronbach's alpha value of 0.96 for an aggregated job satisfaction score (Rothmann, Scholtz, Fourie, \& Rothmann, 2000).

The employee commitment variable was determined with an application of the 'organisational commitment' construct in the Psycones questionnaire (psychological contracts across employment situations; Kerstin, 2002). The organisational commitment scale comprises five scale items, ranging from (1) strongly disagree to (5) strongly agree. A typical item to determine organisational commitment is as follows: 'even if this organisation or client was not doing too well, I would be reluctant to change to another employer or client'. A South African application of the measuring instrument reported a Cronbach's alpha value of 0.72 (Walters, 2008).

The intention to quit dimension was measured by using the 'intention to quit' construct in the Psycones questionnaire as developed by Kerstin (2002). The four-item scale uses a fivepoint Likert scale, ranging from (1) strongly disagree to (5) strongly agree. A typical item to quantify the specific measurement is as follows: 'these days, I often feel like quitting'. A higher score would be an indication of the likelihood of respondents quitting or exiting their current employment, whilst a lower score would be an indication that respondents do not really show a propensity to quit their present employment. A South African application of the measuring instrument recorded a Cronbach's alpha value of 0.93 (Walters, 2008).

\section{Statistical analysis}

The data were captured and analysed by using Statistical Package for Social Sciences (SPSS) (IBM Corp, 2018) version 25.0. An exploratory factor analysis was conducted for each single measured variable in this study. The statistical analysis of the factor analysis included the Kaiser-MeyerOlkin (KMO) measure of sampling adequacy; principal component analysis was used as the extraction method. According to Field (2009), the KMO measure of sampling adequacy could be used to determine whether or not a sample was suitable for factor analysis. A value close to 1 indicates that patterns of correlations are relatively compact and a factor analysis, therefore, should yield distinct, reliable factors (Field, 2009). Eigenvalues larger than 1.00 were used as criteria for factor selection, as proposed by Field (2009). A study by Jackson (2017) administered similar techniques in order to determine separate validity, including an investigation on personal resource, transformational leadership and employee attitudes.

Cronbach's alpha values and inter-item correlations were computed in order to determine reliability. Adequate reliability was considered at $\alpha>0.60=$ moderate (Robinson, Shaver, \& Wrightsman, 1991) and $r=0.10$ for inter-item correlations (Pallant, 2007).

Pearson's correlation values were calculated in order to determine the relationships between variables. Effect sizes 
were set at a confidence level of $99 \%$, with $p<0.01$ viewed as significant. Parameters for the correlation coefficients were considered as exerting a small effect when $r \geq 0.10$, medium effect when $r \geq 0.30$ and large effect when $r \geq 0.50$ (Cohen, 1988).

Mediation modelling was computed by using PROCESS Macros, Version 3 (Hayes, 2017) which was installed in SPSS. Mediation modelling also included standardised regression coefficients in order to determine predictor characteristics of the investigated variables. Servant leadership was considered as the independent variable; diversity climate as the mediator and employee attitudes (organisational commitment, intention to quit and job satisfaction) as dependent variables. Gender and race were included as control variables. Mediation was verified with an indirect effect, using a percentile bootstrap estimation approach by including 10000 samples (Shrout \& Bolger, 2002). An indirect effect from the bootstrap analysis was considered significant if the lower level confidence interval (LLCI) and upper level confidence interval (ULCI) excluded 0 (Zhao, Lynch, \& Chen, 2010). A complementary mediation result could only be determined with existing mediated and direct effects pointing in the same direction (Zhao et al., 2010).

\section{Ethical consideration}

Ethical clearance (NWU-00602-20-A4) to conduct the study was obtained from the North-West University School of Business and Governance.

\section{Results}

The findings of the study are reported in three main sections. The first section reports on validity; the second section reports on reliability and descriptive statistics; whilst the final section reports on correlations, multiple regression and structural equation modelling.

\section{Exploratory factor analysis}

The results gathered from the separate exploratory factor analysis, inspections of scree plots and eigenvalues of the extracted factors indicate that all measurement scales applied in this study could be considered as one-dimensional. Eigenvalues greater than 1.00 were used as criteria for factor selection, as proposed by Field (2009).

The uni-factorial calculations extracted explain $60.60 \%$ of the variance, with an eigenvalue of $5.45(\mathrm{KMO}=0.90)$ in diversity climate. With regard to servant leadership, the uni-factorial solutions extracted explain $71.48 \%$ of the variance in interpersonal support, with an eigenvalue of $4.29(\mathrm{KMO}=0.90)$. The first factor extracted in building community explains $64.97 \%$ of the variance with an eigenvalue of $3.25(\mathrm{KMO}=0.84)$, while in the altruism variable, the first factor expounds $79.15 \%$ of the variance with an eigenvalue of $3.17(\mathrm{KMO}=0.85)$. The egalitarianism factor has $75.56 \%$ of the variance clarified by the first factor extracted, with an eigenvalue of $3.02(\mathrm{KMO}=0.81)$; and the moral integrity factor has $71.63 \%$ of the variance explained by the first factor, with an eigenvalue of 4.30 $(\mathrm{KMO}=0.92)$

The results for the organisational commitment variable reveal the fact that the first factor extracted explains 56.01 of the variance, with an eigenvalue of $2.80(\mathrm{KMO}=0.79)$. The intention-to-quit factor has $77.25 \%$ of the variance explained for the first factor extracted, with an eigenvalue of 3.09 $(\mathrm{KMO}=0.88)$. With regard to the job satisfaction variable, the intrinsic satisfaction factor has $44.21 \%$ of the variance explained by the first factor extracted, with an eigenvalue of 5.31. The extrinsic factor reveals a variance of $56.77 \%$ for the first factor extracted, with an eigenvalue of 3.41 (KMO = 0.79). The general job satisfaction variable has $69.34 \%$ of the variance explained by the first factor extracted, with an eigenvalue of $1.38(\mathrm{KMO}=0.50)$.

\section{Descriptive and reliability results}

Table 2 depicts the results obtained from descriptive and reliability statistical calculations.

According to Table 2, the general job satisfaction $(\alpha=0.58$; $r=0.39$ ) factor documents an alpha score below the set threshold and was therefore removed from further analysis. Reliability scores for the remaining variables were deemed acceptable. Table 2 further demonstrates the fact that the main variables are all in their respective scales' 'agree' range. The results for the diversity climate observation and servant leadership recorded a mean score of 3.39 and 3.55, respectively. The job satisfaction variable recorded a mean score of 3.66, which would suggest that the respondents are fairly satisfied with their current occupation. The intention-to-quit variable recorded a mean score of 2.48 , which would indicate that the respondents from the sample group are not actually demonstrating turnover intention.

TABLE 2: Descriptive and reliability results, servant leadership, diversity climate and employee attitudes.

\begin{tabular}{lcccc}
\hline Variable & Mean & SD & $\begin{array}{c}\text { Cronbach's } \\
\text { alpha }\end{array}$ & $\begin{array}{c}\text { Inter-item } \\
\text { correlation }\end{array}$ \\
\hline Diversity climate & 3.39 & 0.78 & 0.92 & 0.55 \\
Servant leadership & 3.55 & 0.84 & 0.97 & 0.63 \\
Interpersonal support & 3.58 & 0.90 & 0.92 & 0.66 \\
Building community & 3.64 & 0.75 & 0.86 & 0.56 \\
Altruism & 3.46 & 0.93 & 0.91 & 0.72 \\
Egalitarianism & 3.51 & 0.92 & 0.89 & 0.67 \\
Moral integrity & 3.59 & 0.90 & 0.92 & 0.66 \\
Organisational commitment & 4.00 & 0.68 & 0.80 & 0.45 \\
Intention to quit & 2.48 & 1.11 & 0.90 & 0.69 \\
Job satisfaction & 3.66 & 0.61 & 0.92 & 0.37 \\
Intrinsic satisfaction & 3.81 & 0.59 & 0.88 & 0.38 \\
Extrinsic satisfaction & 3.38 & 0.82 & 0.84 & 0.47 \\
General job satisfaction & 3.64 & 0.79 & 0.58 & 0.39 \\
\hline
\end{tabular}

SD, Standard deviation. 
TABLE 3: Correlation analysis: Servant leadership, diversity climate and employee attitudes.

\begin{tabular}{|c|c|c|c|c|c|c|c|c|c|c|c|c|c|}
\hline \multicolumn{2}{|c|}{ Variable } & \multirow{2}{*}{$\begin{array}{l}1 \\
1\end{array}$} & \multirow{2}{*}{2} & \multirow{2}{*}{3} & \multirow{2}{*}{4} & \multirow[t]{2}{*}{5} & \multirow{2}{*}{6} & \multirow{2}{*}{7} & \multirow{2}{*}{8} & \multirow{2}{*}{$\begin{array}{l}9 \\
-\end{array}$} & \multirow{2}{*}{10} & \multirow{2}{*}{$\frac{11}{-}$} & \multirow{2}{*}{$\frac{12}{-}$} \\
\hline 1 & Diversity climate & & & & & & & & & & & & \\
\hline 2 & Servant leadership & $0.41 *$ & 1 & - & - & - & - & - & - & - & - & - & - \\
\hline 3 & Interpersonal support & $0.38 *$ & $0.97 *$ & 1 & - & - & - & - & - & - & - & - & - \\
\hline 4 & Building community & $0.48 *$ & $0.91 *$ & $0.86 *$ & 1 & - & - & - & - & - & - & - & - \\
\hline 5 & Altruism & $0.38 *$ & $0.95 *$ & $0.90 *$ & $0.83 *$ & 1 & - & - & - & - & - & - & - \\
\hline 6 & Egalitarianism & $0.34 *$ & $0.94 *$ & $0.91 *$ & $0.78 *$ & $0.85 *$ & 1 & - & - & - & - & - & - \\
\hline 8 & Organisational commitment & $0.34 *$ & $0.36 *$ & $0.34 *$ & $0.35 *$ & $0.33 *$ & $0.35 *$ & $0.35 *$ & 1 & - & - & - & - \\
\hline 9 & Intention to quit & $-0.20 *$ & $-0.36 *$ & $-0.40 *$ & $-0.34 *$ & $-0.32 *$ & $-0.35 *$ & $-0.37 *$ & $-0.45 *$ & 1 & - & - & - \\
\hline 10 & Job satisfaction & $0.32 *$ & $0.67 *$ & $0.65 *$ & $0.60 *$ & $0.63 *$ & $0.65 *$ & $0.65 *$ & $0.52 *$ & $-0.53 *$ & 1 & - & - \\
\hline 11 & Intrinsic job satisfaction & $0.30 *$ & $0.55^{*}$ & $0.51 *$ & $0.52 *$ & $0.50 *$ & $0.54 *$ & $0.53 *$ & $0.52 *$ & $-0.45 *$ & $0.94 *$ & 1 & - \\
\hline 12 & Extrinsic job satisfaction & $0.29 *$ & $0.74 *$ & $0.74 *$ & $0.63 *$ & $0.72 *$ & $0.71 *$ & $0.72 *$ & $0.41 *$ & $-0.53 *$ & $0.90^{\mathrm{a}}$ & $0.72^{\mathrm{a}}$ & 1 \\
\hline
\end{tabular}

*, Correlation is significant at the 0.01 level (two-tailed); $b$, regression coefficient.

Results were interpreted as: $01=$ small effect; $0.3=$ medium effect and $0.5=$ great effect.

\section{Correlation analysis}

Table 3 shows the results obtained from the correlation analysis. The purpose of the correlation analysis was to determine the extent and direction of the relationships between the variables under investigation.

Characteristics from servant leadership recorded significant correlations with diversity climate (Table 3). The correlations range from $r=0.38$ to $r=0.48$, with all relationships considered as medium practical effect. The relationship between servant leadership (aggregate) and diversity climate also yields a positive result $(r=0.41$, medium). Features of servant leadership further demonstrate significant relationships with employee attitudes. Servant leadership recorded a positive relationship with organisational commitment $(r=0.36$, medium) and job satisfaction $(r=-0.67$, large). The relationship between servant leadership and intention to quit demonstrates an inverse relationship $(r=-0.36$, medium). This result indicates that higher levels of servant leadership within the sample would be associated with lower feelings of turnover intention.

Diversity climate recorded positive associations with organisational commitment $(r=0.34)$ and job satisfaction $(r=0.32)$, with both relationships considered as medium. Furthermore, diversity climate has an inverse relationship with intention to quit $(r=-0.20)$, which is interpreted as a medium effect. This would imply that respondents who indicated a positive perception towards diversity climate would most probably also be associated with lower levels of intention to quit.

\section{Simple mediation modelling}

Three independent simple mediation models were tested by using PROCESS (Hayes, 2017). Servant leadership was considered as the independent variable in each model, while diversity climate was considered as the proposed mediator. The dependent variables were considered as organisational commitment, intention to quit and job satisfaction. Both gender and ethnicity were included as control variables. The results for the three independent models are presented in Table 4 .
Table 4 reveals that only model 1 demonstrates adequate evidence to consider diversity climate as a mediator in the relationship between servant leadership and organisational commitment. Neither model 2 nor model 3 yields a significant result when considering the indirect effect of servant leadership on intention to quit and job satisfaction individually through diversity climate.

Model 1 reveals the first regression (a) where servant leadership (independent variable) and diversity climate (mediator) reveal a significant result with $b=0.39, t$ $(225)=6.74, p<0.01$. The second regression (b) with diversity climate (mediator) and organisational commitment (dependent variable) is also significant with $b=0.20$, $t(224)=3.43, p<0.01$; while the third regression (c) is also significant where servant leadership is considered the independent variable and organisational commitment the dependent variable, with $b=0.22, t(224)=3.98, p<0.01$. The results for the indirect effect reveal a significant result, with $b=0.08$, standard error $(S E)=0.03, L L C I=0.03$ and $U L C I=$ 0.15 . The indirect effect from the bootstrap analysis, with $95 \%$ confidence interval, did not include 0 ; therefore, $(a \times b)$ is significant. Consequently, diversity climate can be considered as a mediator in the relationship between servant leadership and organisational commitment. All three pathways ( $a, b$ and $c)$ are significant and positive; for that reason, the mediation model is considered a 'complementary mediation' model as recommended by Zhao et al. (2010). The results for model 1 are demonstrated in Figure 2.

Model 2 indicates that the first regression (a) with servant leadership and diversity climate (mediator) demonstrates a significant result with $b=0.39, t(225)=6.74, p<0.01$. The second regression (b) with diversity climate (mediator) and intention to quit (dependant variable) is not significant, with $b=-0.06, t(224)=-0.61, p=0.54$; while the third regression (c) yields a significant result where servant leadership is considered as the independent variable, and intention to quit as the dependent variable, with $b=-0.48, t(224)=-5.30$, $p<0.01$. The results for the indirect effect do not reveal a significant result, with $b=-0.02, S E=0.04, L L C I=-0.10$ and $U L C I=0.06$. The values between the confidence interval include 0; therefore, diversity climate cannot be considered a mediator in the relationship between servant leadership and 
TABLE 4: Standardised regression coefficients of the variables: Servant leadership, diversity climate and employee attitudes. Variables Estimate

\begin{tabular}{|c|c|c|c|c|}
\hline \multirow[t]{2}{*}{ Variables } & \multirow[t]{2}{*}{ Estimate } & \multirow[t]{2}{*}{ SE } & \multicolumn{2}{|c|}{$\begin{array}{l}\text { Bootstrapping BC } \\
95 \% \mathrm{Cl}\end{array}$} \\
\hline & & & Lower & Upper \\
\hline \multicolumn{5}{|c|}{ Model 1: Servant leadership, diversity climate and organisational commitment } \\
\hline $\begin{array}{l}\text { Servant leadership } \rightarrow \\
\text { Diversity climate (a) }\end{array}$ & $0.39 *$ & 0.06 & 0.27 & 0.50 \\
\hline $\begin{array}{l}\text { Diversity climate } \rightarrow \\
\text { Organisational commitment (b) }\end{array}$ & $0.20 *$ & 0.06 & 0.09 & 0.32 \\
\hline $\begin{array}{l}\text { Servant leadership } \rightarrow \\
\text { Organisational commitment (c) }\end{array}$ & $0.22 *$ & 0.05 & 0.11 & 0.32 \\
\hline Servant leadership to organisational commitment via diversity climate & 0.08 & 0.03 & 0.03 & 0.15 \\
\hline \multicolumn{5}{|l|}{ Model 2: Servant leadership, diversity climate and intention to quit } \\
\hline $\begin{array}{l}\text { Servant leadership } \rightarrow \\
\text { Diversity climate (a) }\end{array}$ & $0.39 *$ & 0.06 & 0.27 & 0.50 \\
\hline $\begin{array}{l}\text { Diversity climate } \rightarrow \\
\text { Intention to quit (b) }\end{array}$ & -0.06 & 0.10 & -0.26 & 0.12 \\
\hline $\begin{array}{l}\text { Servant leadership } \rightarrow \\
\text { Intention to quit (c) }\end{array}$ & $-0.48 *$ & 0.09 & -0.65 & -0.30 \\
\hline \multicolumn{5}{|l|}{ Model 3: Servant leadership, diversity climate and job satisfaction } \\
\hline $\begin{array}{l}\text { Servant leadership } \rightarrow \\
\text { Diversity climate }(a)\end{array}$ & $0.39 *$ & 0.06 & 0.27 & 0.50 \\
\hline $\begin{array}{l}\text { Diversity climate } \overrightarrow{ } \\
\text { Job satisfaction (b) }\end{array}$ & 0.03 & 0.04 & -0.05 & 0.11 \\
\hline $\begin{array}{l}\text { Servant leadership } \rightarrow \\
\text { Job satisfaction (c) }\end{array}$ & $0.48 *$ & 0.04 & 0.40 & 0.55 \\
\hline Servant leadership to job satisfaction via diversity climate & 0.01 & 0.02 & -0.03 & 0.06 \\
\hline
\end{tabular}

$\mathrm{SE}$, standard error; $\mathrm{BC}$, bias corrected; $\mathrm{Cl}$, confidence interval.

$*$, Regression is considered significant at $p<0.05$.

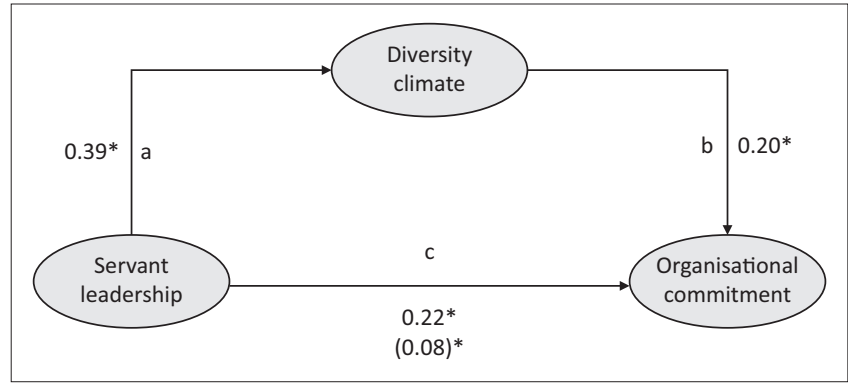

Note: Value in parentheses represents the indirect effect of servant leadership via diversity climate on job satisfaction. BC: bias corrected bootstrap approximation at $95 \%$ corrected confidence interval (two-sided). $N=230$

$*$, Standardised path coefficients are significant at $p<0.05$.

FIGURE 2: Simple mediation model 1: Servant leadership, diversity climate and organisational commitment.

intention to quit. The results from model 2 are illustrated in Figure 3.

The results from model 2 indicate that the first regression (a) with servant leadership and diversity climate (mediator) is significant, with $b=0.39, t(225)=6.75, p<0.01$. The second regression (b) with diversity climate (mediator) and job satisfaction (dependant variable) is not significant, with $b=0.03, t(224)=0.66, p=0.51$; while the third regression (c) produced a significant result where servant leadership is considered the independent variable and job satisfaction the dependent variable, with $b=0.48, t(224)=12.14$, $p<0.01$. The results for the indirect effect do not reveal a significant result, with $b=0.01, S E=0.02, L L C I=-0.03$ and $U L C I=0.06$. The values amidst the confidence interval included 0 ; therefore, diversity climate cannot be considered as a mediator in the relationship between servant

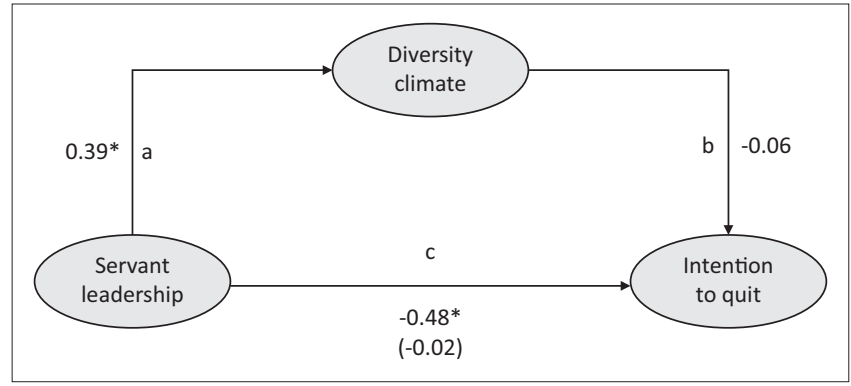

Note: Value in parentheses represents the indirect effect of servant leadership via diversity climate on job satisfaction. BC: bias corrected bootstrap approximation at $95 \%$ corrected confidence interval (two-sided). $N=230$

*, Standardised path coefficient are significant at $p<0.05$.

FIGURE 3: Simple mediation model 2: Servant leadership, diversity climate and intention to quit.

leadership and intention to quit. The results of model 3 are illustrated in Figure 4.

\section{Discussion}

The objectives of the study were to examine three separate mediating models with diversity climate considered as the mediator in the relationship between servant leadership and employee attitudes. The objectives further included an investigation into the relationships, including direct effects between servant leadership, diversity climate and the investigated employee outcomes (organisational commitment, intention to quit and job satisfaction). The objectives aimed at answering the following research questions:

- What is the type and nature of the relationship between servant leadership, diversity climate and employee attitudes? 


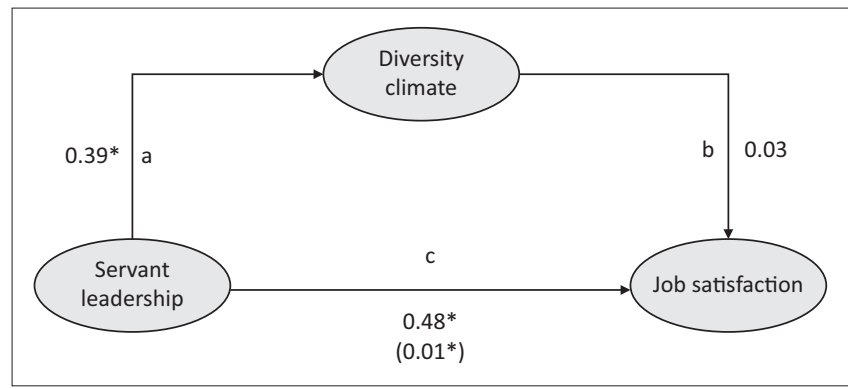

Note: Value in parentheses represents the indirect effect of servant leadership via diversity climate on job satisfaction. BC: bias corrected bootstrap approximation at $95 \%$ corrected confidence interval (two-sided). $N=230$.

*, Standardised path coefficient are significant at $p<0.05$.

FIGURE 4: Simple mediation model 3: Servant leadership, diversity climate and job satisfaction.

- What is the impact of servant leadership on diversity climate?

- What is the effect of diversity climate on employee attitudes?

- What is the impact of servant leadership on employee attitudes?

- What is the indirect effect of servant leadership on employee attitudes through diversity climate?

The results reveal that servant leadership has a significant positive relationship with diversity climate. This would translate to a situation where beneficial levels of servant leadership would also be associated with a constructive amount of diversity climate. In addition, servant leadership demonstrates a significant and positive direct effect with diversity climate, which translates into a situation where higher recordings of servant leadership would also result in a conducive diversity climate. The results of the present study confirm previous findings of Gotsis and Grimani (2016) and Van Dierendonck (2011) who stated that servant leadership is highly related to cultures and climates for inclusion. Therefore, the present study further contributes to limited literature on diversity climate, providing empirical evidence that servant leadership can be associated with constructive levels of diversity climate; at the same time, positive levels of servant leadership are also likely to predict higher levels of diversity climate. Servant leadership symbolises an ethical element to such an extent that servant leaders are considered as individuals who set more humane ideals for individuals respecting diverse employees (Gotsis \& Grimani, 2016).

Servant leadership further demonstrates a statistically significant and positive medium practical relationship with organisational commitment and an inverse medium practical relationship with employee's intention to quit. These results imply that within the South African sample group, higher recordings of servant leadership would be associated with employees who are more committed and demonstrate a reduced propensity of quitting their current employment. The examinations of direct effects further demonstrate servant leadership to have a direct positive effect on organisational commitment and job satisfaction, and an inverse direct effect on employees' intention to quit.
The results would translate into a situation where improved observations of servant leadership would result in improved levels of organisational commitment and job satisfaction, and would further result in employees not showing intentions to quit. The findings confirm previous investigations that servant leadership would be associated with improved organisational commitment (Jang \& Kandampully, 2018) and intentions not to quit (Brohi et al., 2018). Servant leadership recordings also demonstrate a statistically significant and practically strong relationship with job satisfaction, therefore confirming the previous findings of Cerit (2009).

The findings pertaining to the relationships between diversity climate, organisational commitment, intention to quit and job satisfaction reveal servant leadership to have a positive relationship with organisational commitment and job satisfaction. Diversity climate further has an inverse relationship with employee's intentions to quit. The present study supports previous findings indicating diversity climate to be positively associated with organisational commitment (Gonzalez \& Denisi, 2009) and job satisfaction (Choi, 2013), and further demonstrates associations with non-intentions to quit (Gonzalez \& Denisi, 2009). These results suggest that higher observations of diversity climate of respondents within the sample group would also be associated with higher recordings of organisational commitment and job satisfaction, and lower recordings of intention to quit. Although these results should be considered as positive, the study was only able to find evidence that a constructive diversity climate would positively impact levels of organisational commitment.

The results of the three separate mediation models could only provide evidence that servant leadership would have an indirect effect on organisational commitment via diversity climate. Evidence could not be obtained to indicate a significant indirect effect of servant leadership on intention to quit, and job satisfaction via diversity climate. Previous findings offer evidence to suggest the fact that diversity climate would mediate the relationship between a positive form of leadership (transformational) and organisational commitment (McCallaghan et al., 2019a). The present study confirms the mediating characteristics of diversity climate in the relationship of a positive form of leadership (servant leadership in the case of the present study) and organisational commitment.

\section{Theoretical and practical implications for human resource practitioners}

This study extends the diversity climate literature by obtaining evidence from a South African sample that servant leadership impacts diversity climate. It is widely known that policies and practices related to effective diversity management are considered traditional antecedents of diversity climate (McKay \& Avery, 2015). McKay and Avery (2015) have also called on researchers to examine nontraditional antecedents of diversity climate, for example, leadership. The present contribution demonstrates direct effects and positive associations between characteristics of servant leadership and a constructive diversity climate. As a 
supplement to effective diversity policies and practices, organisations should further benefit on the diversity front by implementing strategic development initiatives in terms of interpersonal employee support, community building, greater acts of humanity, increased observations of tangible fairness and moral integrity.

While well-formulated and governed policies and practices are important contributing factors towards an improved diversity climate, organisations should also manage diversity beyond normal legislative requirements (Gotsis \& Kortezi, 2015). For organisations to experience the full benefit of a diversity climate, they are required to focus on discrimination and social justice improvement, as this will improve employee perceptions in terms of the total commitment towards diversity (Gotsis \& Kortezi, 2015). The current study offers evidence that although servant leadership might be sufficient to reduce employees' intention to quit their current occupations and improve their job satisfaction, managers and leaders would have to carefully consider how employees form perceptions regarding diversity, especially when attempting to improve organisational commitment. Therefore, managing diversity beyond legislative requirement can assist organisations in improving organisational commitment, especially when employees are subjected to servant leadership behaviours. The findings, therefore, contribute to limited literature related to diversity climate, especially when examining the indirect effect of diversity climate on the relationship between servant leadership and employee attitudes.

\section{Limitations and future research}

We are realistic in accepting that the present study was not faultless. The quantitative cross-sectional approach reflects servant leadership, diversity climate and employee outcomes at a single point in time. Although cross-sectional investigations are valuable in identifying certain observations at a single point in time (Spector, 2019), the long-term causal effect of diversityrelated interventions can only be confirmed with repeated examinations over time. For example, future studies might consider examining the observation of new employees with regard to servant leadership, diversity climate and employee outcomes consequently re-examining the same employees after a considerable employment period. Furthermore, a convenience sampling method was used to gather data and as a result, population generalisation could not be considered. Future studies should consider a mixed-method approach with a stratified sampling technique, especially when investigating gender and ethnic differences within servant leadership.

The low reliability score for the general job satisfaction variable might be a result of low scale items; however, rephrasing the items with a test or retest method should be considered in future studies. Given the association between servant leadership and high morality, future studies should consider alternative leadership forms that also resemble high levels of morality and integrity when investigating relationships with diversity climate. Authentic and ethical leadership behaviour could be considered in this regard. Employee outcomes were restricted to individual attitudes and future South African studies should perhaps consider performance indicators as model outputs, including ethical behaviour and indicators of integrity.

Because of self-report questionnaires and noticeable correlations between variables, common source bias is also identified as a limitation of the study. In order to mitigate common source bias, future studies should consider careful assessment of the research setting, identify possible sources of bias and apply both procedural and statistical methods to control for common source bias (Podsakoff, Mackenzie, \& Lee, 2003). Future studies could perhaps consider a mixedmethod approach in order to confirm or dismiss quantitative outcomes.

The present study covered a wide range of industries; future studies should consider focusing on one specific industry in order to formulate better understandings on how diversity climate operates in specific industries.

\section{Conclusion}

This study helped confirm the fact that conducive levels of servant leadership should be able to positively impact levels of job satisfaction and decrease levels of an employee's intention to quit. However, the presence of servant leadership would not be sufficient to improve organisational commitment; what is also required are positive shared perceptions on how well the organisation manages and values diversity.

\section{Acknowledgements Competing interests}

The authors have declared that no competing interests exist.

\section{Authors' contributions}

S.M. conducted the literature review, collected and processed all data and was responsible for the write-up of the article. L.J. and M.H. guided the conceptualisation and interpretation of results, provided a commentary and coauthored the article.

\section{Funding information}

This research received no specific grant from any funding agency in the public, commercial or not-for-profit sectors.

\section{Data availability statement}

Data sharing is not applicable to this article as no new data were created or analysed in this study.

\section{Disclaimer}

The views and opinions expressed in this article are those of the authors and do not necessarily reflect the official policy or position of any affiliated agency of the authors. 


\section{References}

Albrecht, S.L., Bakker, A.B., Gruman, J.A., Macey, W.H., \& Saks, A.M. (2015). Employee engagement, human resource management practices and competitive advantage: Performance, 2(1), 7-35. https://doi.org/10.1108/JOEPP-08-2014-0042

Allen, N., \& Meyer, J. (1996). Affective, continuance and normative commitment to the organisation: An examination of construct validity. Journal of Vocational Behaviour, 49(3), 252-276. https://doi.org/10.1006/jvbe.1996.0043

Anand, R., \& Winters, M.F. (2008). A retrospective view of corporate diversity training from 1964 to present. Academy of Management Learning \& Education, 7(3), 356-371. https://doi.org/10.5465/amle.2008.34251673

Bakotić, D. (2016). Relationship between job satisfaction and organisational performance. Economic Research-Ekonomska Istraživanja, 29(1), 118-130. https://doi.org/10.1080/1331677X.2016.1163946

Booysen, L.A.E., \& Nkomo, S.M. (2010). Gender role stereotypes and requisite management characteristics: The case of South Africa. Gender in Management: An International Journal, 25(4), 285-300. https://doi.org/10.1108/ 17542411011048164

Boshoff, A.B., Van Wyk, R., Hoole, C., \& Owen, J.H. (2002). The prediction of intention to quit by means of biographic variables, work commitment, role strain and psychological climate. Management Dynamics, 11(4), 14-28.

Bothma, F.C., \& Roodt, G. (2012). Work based identity and work engagement as potential antecedents of task performance and turnover intention: Unravelling a complex relationship. South African Journal of Industrial Psychology, 38(1), 1-17. https://doi.org/10.4102/sajip.v38i1.893

Brimhall, K.C., Lizano, E.L., \& Mor Barak, M.E. (2014). The mediating role of inclusion: A longitudinal study of the effects of leader-member exchange and diversity climate on job satisfaction and intention to leave among child welfare workers. Children and Youth Services Review, 40, 79-88. https://doi.org/10.1016/j. childyouth.2014.03.003

Brohi, N.A., Jantan, A.H., Sobia, A.M.S., \& Pathan, T.G. (2018). Does servant leadership style induce positive organisational behaviors? A conceptual study of servant
leadership, psychological capital, and intention to quit relationship. Journal of leadership, psychological capital, and intention to
International Business and Management, 1(1), 1-11.

Budhram, T., \& Geldenhuys, N. (2018). Combating corruption in South Africa: Assessing the performance of investigating and prosecuting agencies. Acto Criminologica: South African Journal of Criminology, 31(2), 23-46.

Carter, D., \& Baghurst, T. (2014). The influence of servant leadership on restaurant employee engagement. Journal of Business Ethics, 124(3), 453-464. https://doi. org/10.1007/s10551-013-1882-0

Cerit, Y. (2009). The effects of servant leadership behaviours of school principals on teachers' job satisfaction. Educational Management Administration \& Leadership, 37(5), 600-623. https://doi.org/10.1177/1741143209339650

Chan, S.C., \& Mak, W. (2014). The impact of servant leadership and subordinates' organizational tenure on trust in leader attitudes. Personnel Review, 43(2), 272287. https://doi.org/10.1108/PR-08-2011-0125

Chatzoglou, P.D., Vraimaki, E., Komsiou, E., Polychrou, E., \& Diamantidis, A.D. (2011) Factors affecting accountants' job satisfaction and turnover intentions: A structural equation model. Paper Presented at the 8th International Conference structural equation model. Paper Presented at the 8th International Conference on Enterprise Systems, Accounting and Logistics, 11-12 July 2011. Greece: Thassos
Island. Retrieved from https://www.researchgate.net/publication/257230548 Factors_Affecting_Accountants'_Job_Satisfaction_and_Turnover_Intentions_A Factors_Affecting_Accountants

Chin, J. L., Desormeaux, L., \& Sawyer, K. (2016). Making way for paradigms of diversity leadership. Consulting Psychology Journal: Practice and Research, 68(1), 49-71.

Chiniara, M., \& Bentein, K. (2016). Linking servant leadership to individual performance: Differentiating the mediating role of autonomy, competence and relatedness need satisfaction. The Leadership Quarterly, 27(1), 124-141.https:// doi.org/10.1016/j.leaqua.2015.08.004

Choi, S. (2013). Demographic diversity of managers and employee job satisfaction Review of Public Personnel Administration, 33(3), 275-298. https://doi. org/10.1177/0734371X12453054

Choudhary, A.I., Akhtar, S.A., \& Zaheer, A. (2013). Impact of transformational and servant leadership on organizational performance: A comparative analysis. Journal of Business Ethics, 116(20), 433-440. https://doi.org/10.1007/s10551 012-1470-8

Coetzer, M.F., Bussin, M., \& Geldenhuys, M. (2017). The functions of a servant leader Administrative Sciences, 7(5), 1-32. https://doi.org/10.3390/admsci7010005

Cohen, J. (1988). Statistical power analysis for behavioural science (2nd edn.). Hillside, NJ: Erlbaum.

Colquitt, J.A., Lepine, J.A., \& Wesson, M.W. (2011). Organisational behaviour: Improving performance and commitment in the workplace (2nd edn.). New York, NY: McGraw-Hill.

Covey, S.R. (2006). Servant leadership: Use your voice to serve others. Leadership Excellence, 23(12), 5-6.

Curtis, S., \& Wright, D. (2001). Retaining employees: The fast track to commitment. Management Research News, 24(8/9), 59-64. https://doi.org/10.1108/014091
70110782964

Durrheim, K., \& Talbot, K. (2012). The Princeton trilogy revisited: How have racial stereotypes changed in South Africa? South African Journal of Psychology, 42(4), 476-491. https://doi.org/10.1177/008124631204200403

Ehrhart, M.G. (2004). Leadership and procedural justice climate as antecedents of unit-level organizational citizenship behaviour. Personnel Psychology, 57(1), 6196. https://doi.org/10.1111/j.1744-6570.2004.tb02484.x
Field, A. (2009). Discovering statistics using SPSS (3rd edn.). London: Sage.

Foster, C., \& Harris, L. (2005). Easy to say, difficult to do: Diversity management in retail. Human Resource Management Journal, 15(3), 4-17. https://doi.org/10. 1111/j.1748-8583.2005.tb00150.x

Gonzalez, J.A., \& Denisi, A.S. (2009). Cross-level effects of demography and diversity climate on organizational attachment and firm effectiveness. Journal of Organizational Behaviour, 30(1), 21-40. https://doi.org/10.1002/job.498

Gotsis, G., \& Grimani, K. (2016). The role of servant leadership in fostering inclusive organizations. Journal of Management Development, 35(8), 985-1010. https:// doi.org/10.1108/JMD-07-2015-0095

Gotsis, G., \& Kortezi, Z. (2015). Critical studies in diversity management literature. A review and synthesis. New York, NY: Springer.

Greenleaf, R.K. (1977). Servant leadership: A journey into the nature of legitimate power and greatness. New York, NY: Paulist Press.

Hale, R.K., \& Fields, D.L. (2007). Exploring servant leadership across cultures: A study of followers in Ghana and the USA. Leadership, 3(4), 397-417. https://doi. org/10.1177/1742715007082964

Hayes, A.F. (2017). Introduction to mediation, moderation, and conditional process analysis: A regression-based approach. New York, NY: Guilford Publications.

Hicks-Clarke, D., \& Iles, P. (2000). Climate for diversity and its effects on career and organisational attitudes and perceptions. Personnel Review, 29(3), 324-345. https://doi.org/10.1108/00483480010324689

Hofhuis, J., Van der Rijt, P.G.A., \& Vlug, M. (2016). Diversity enhances work outcomes through trust and openness in workgroup communication. SpringerPlus, 5(714), through trust and openness in workgroup communich
$1-14$. https://doi.org/10.1186/s40064-016-2499-4

Hofhuis, J., Van der Zee, K.I., \& Otten, S. (2012). Social identity patterns in culturally diverse organisations: The role of diversity climate. Journal of Applied Socia Psychology, 42(4), 964-989. https://doi.org/10.1111/j.1559-1816.2011.00848.x

$\mathrm{Hu}$, J., \& Liden, R.C. (2011). Antecedents of team potency and team effectiveness: An examination of goal and process clarity and servant leadership. Journal of Applied Psychology, 96(4), 851-862. https://doi.org/10.1037/a0022465

Hunter, E.M., Neubert, M.J., Perry, J.S., Witt, L.A., Penney, L.M., \& Weinberger, E. (2013). Servant leadership inspires servant followers: Antecedents and outcomes for employees and the organization. The Leadership Quarterly, 24(2), 316-331. https://doi.org/10.1016/j.leaqua.2012.12.001

IBM Corp. (2018). IBM SPSS Statistics for Windows, version 25.0. Armonk, NY: IBM Corp.

Jackson, L.T.B. (2017). The mediating role of personal resources in the relationship between transformational leadership and employee attitude. In C.A. Bisschoff, \& J. Jordaan (Eds.), 2017 International Business Conference Proceedings, Dar Es Salaam, Tanzania (pp. 569-608). North-West University. Retrieved from http://ibcSalaam, Tanzania (pp. 569
conference.com/2017-ibc/

Jackson, L.T.B., Van de Vijver, F.J.R., \& Molokoane, D.H. (2013). A dualprocess model of diversity outcomes: The case South African police service in the Pretoria area. SA Journal of Human Resource Management, 11(1), 1-13.

Jaga, A., Arabandi, B., Bagraim, J., \& Mdlongwa, S. (2018). Doing the 'gender dance' Black women professionals negotiating gender, race, work and family in postapartheid South Africa. Community Work \& Family, O(0), 1-16.

Jang, J., \& Kandampully, J. (2018). Reducing employee turnover intention through servant leadership in the restaurant context: A mediation study of affective organizational commitment. International Journal of Hospitality \& Tourism Administration, 19(2), 125-141. https://doi.org/10.1080/15256480.2017.1305310

Jayne, M.E.A., \& Dipboye, R.L. (2004). Leveraging diversity to improve business performance: Research findings and recommendations for organizations. Huma Resource Management, 43(4), 409-424. https://doi.org/10.1002/hrm.20033

Joshi, A., \& Roh, H. (2009). The role of context in work team diversity research: A meta-analytic review. Academy of Management Journal, 52(3), 599-627. https:// meta-analytic review. Academy of Mand
doi.org/10.5465/amj.2009.41331491

Joubert, Y.T. (2017). Workplace diversity in South Africa: Its qualities and management. Journal of Psychology in Africa, 27, 367-371.

Kaplan, D.M., Wiley, J.W., \& Maertz, C.P. (2011). The role of calculative attachment in the relationship between diversity climate and retention. Human Resource Management, 50(2), 271-287. https://doi.org/10.1002/hrm.20413

Kerstin, I. (2002). Psychological contracts across employment situations (Psycones). Stockholm: Institute for Working Life.

Kgatle, M.S. (2018). Servant leadership: An urgent style for the current political leadership in South Africa. Verbum et Ecclesia, 39(1), 1-12. https://doi.org/ leadership in South A
$10.4102 /$ ve.v39i1.1815

Kool, M., \& van Dierendonck, D. (2012). Servant leadership and commitment to change, the mediating role of justice and optimism. Journal of Organizational Change Management, 25(3), 422-433. https://doi.org/10.1108/09534811211228139

Leem, T.J. (2015). The relationship between servant leadership and the diversity of performance measures. Indian Journal of Science and Technology, 8(S1), 254-260. https://doi.org/10.17485/ijst/2015/v8iS1/59023

Liden, R.C., Wayne, S.J., Zhao, H., \& Henderson, D. (2008). Servant leadership: Development of a multidimensional measure and multi-level assessment. Leadership Quarterly, 19(2), 161-177. https://doi.org/10.1016/j.leaqua.2008.01.006

Luthans, F., \& Avolio, B. (2003). Authentic leadership development. In K.S. Cameron \& J.E. Dutton (Eds.), Positive organisational scholarship (pp. 241-258). San Francisco, CA: Berrett-Koehler.

Madera, J.M., Dawson, M., \& Neal, J.A. (2013). Hotel managers' perceived diversity climate and job satisfaction: The mediating effects of role ambiguity and conflict. International Journal of Hospitality Management, 35, 28-34. https://doi.org/ 10.1016/j.ijhm.2013.05.001 
McCallaghan, S., Jackson, L.T.B., \& Heyns, M.M. (2019a). Exploring organisational diversity climate with associated antecedents and employee outcomes. South African Journal of Industrial Psychology, 45(0), 1-10. https://doi.org/10.1080/143 30237.2019.1619994

McCallaghan, S., Jackson, L.T.B., \& Heyns, M.M. (2019b). Transformational leadership, diversity climate and job satisfaction in selected South African companies. Journa of Psychology in Africa, 29(3), 195-202. https://doi.org/10.1080/14330237.2019. 1619994

McKay, P.F., \& Avery, D.R. (2015). Diversity climate in organizations: Current wisdom and domains of uncertainty. Research in Personnel and Human Resource Management, 33, 191-233.

McKay, P.F., Avery, D.R., Tonidandel, S., Morris, M.A., Hernandez, M., \& Hebl, M.R (2007). Racial differences in employee retention: Are diversity climate perception key? Personnel Psychology, 60(1), 35-62. https://doi.org/10.1111/j.1744-6570. 2007.00064.x

Mor Barak, M.E., Cherin, D.A., \& Berkman, S. (1998). Organizational and persona dimensions in diversity climate: Ethnic and gender differences in employee attitudes. The Journal of Applied Behavioural Sciences, 34(1), 82-104. https://doi.org/ 10.1177/0021886398341006

Mowday, R.T., Porter, L.M., \& Steers, R.M. (1982). Employee-organization linkages New York, NY: Academic Press.

Ogbonna, E., \& Harris, L.C. (2006). The dynamics of employee relationships in an ethnically diverse workforce. Human Relations, 59(3), 379-407. https://doi. ethnically diverse workforce. Hum
org/10.1177/0018726706064181

Ojukwu, C., \& Oni, E.O. (2017). Multiculturalism, racialism and the dilemma of the African-American in the twenty-first century. AFFRIKA Journal of Politics, Economics and Society, 7(1), 111-126. https://doi.org/10.31920/2075-6534/2017/v7n1a6

Pallant, J. (2007). SPSS survival manual. A step by step to data analysis using SPSS for windows (7th edn.). New York, NY: McGraw-Hill.

Panaccio, A., Donia, M., Saint-Michel, S., \& Liden, R.C. (2015). Servant leadership and well-being. In R.J. Burke, K.M. Page \& C.L. Cooper (Eds.), Flourishing in life, work and careers (pp. 334-358). Cheltenham: Edward Elgar.

Parks, K.M., Crepeau, L.J., Knouse, S.B., \& McDonald, D.P. (2008). Latina perceptions of diversity climate in the military. Business Journal of Hispanic Research, 2(3), 48-61.

Parris, D.L., \& Peachy, J.W. (2013). A systematic literature review of servant leadership theory in organizational contexts. Journal of Business Ethics, 113, 377-393. https://doi.org/10.1007/s10551-012-1322-6

Podsakoff, P.M., Mackenzie, S.B., \& Lee, J. (2003). Common method biases in behavioral research: A critical review of the literature and recommended remedies. Journal of Applied Psychology, 88(5), 879-903. https://doi org/10.1037/0021-9010.88.5.879

Pugh, S.D., Dietz, J., Brief, A.P., \& Wiley, J.W. (2008). Looking inside out: The impact of employee and community demographic composition on organizational diversity climate. Journal of Applied Psychology, 93(6), 1422-1428. https://doi. org/10.1037/a001269

Reed, L.L., Cohen, D.V., \& Colwell, S.R. (2011). A new scale to measure executive servant leadership. Journal of Business Ethics, 101, 415-434. https://doi.org/ 10.1007/s10551-010-0729-1

Richard, O.C., Stewart, M.M., McKay, P.F., \& Sacket, T. (2017). The impact of store-unitcommunity racial diversity congruence on store-unit sales performance. Journal of Management, 43(7), 2386-2403. https://doi.org/10.1177/0149206315579511

Robinson, J.P., Shaver, P.R., \& Wrightsman, L.S. (1991). Criteria for scale selection and evaluation. In J.P. Robinson, P.R. Shaver \& L.S. Wrightsman (Eds.), Measures of personality and social psychological attitudes (pp. 1-16). San Diego, CA: Ácademic Press.
Rothmann, S., Scholtz, P.E., Fourie, M., \& Rothmann, J.C. (2000). The relationship between individual variables and work-related outcomes. Potchefstroom: Potchefstroom University for Christian Higher Education.

Shrout, P.E., \& Bolger, N. (2002). Mediation in experimental and nonexperimental studies: New procedures and recommendations. Psychological Methods, 7(4), 422-445. https://doi.org/10.1037/1082-989X.7.4.422

Spector, P.E. (2019). Do not cross me: Optimising the use of cross-sectional designs. Journal of Business Psychology, 34(3), 125-137. https://doi.org/10.1007/s10869018-09613-8

Statistics South Africa. (2018). Quarterly labour force survey, quarter Q1, 2018. Retrieved from https://www.statssa.gov.za/publications/P0211/P02111stQuarter2018.pdf.

Suliman, A., \& lles, P. (2000). Is continuance commitment beneficial to organisations? Commitment-performance relationship: A new look. Journal of Managerial Psychology, 15(5), 407-426. https://doi.org/10.1108/02683940010337158

Süß, S., \& Kleiner, M. (2007). Diversity management in Germany: Dissemination and design of the concept. The International Journal of Human Resource Management, 18(11), 1934-1953. https://doi.org/10.1080/09585190701638150

Van Dierendonck, D., \& Nuijten, I. (2011). The servant leadership survey: Development and validation of a multidimensional measure. Journal of Business Psychology, 26, 249-267.

Van Dijk, H, van Engen, M.L. \& van Knippenberg, D. (2012). Defying conventional wisdom: Meta-analytical examination of the differences between demographic and job related diversity relationships with performance. Organizational Behavio and Human Decision Making Processes, 119(1), 38-53. https://doi.org/10.1016/j. obhdp.2012.06.003

Van Heerden, L.D. (2015). The relationship between servant leadership and ethica work climate in an agri-business. Unpublished Master's Dissertation, North-West University, Potchefstroom.

Van Heerden, L.D. (2015). The relationship between servant leadership and ethica work climate in an agri-business (unpublished master's dissertation). North-West University, Potchefstroom.

Vandenberghe, C., Bentein, K., \& Stinglhamber, F. (2004). Affective commitment to the organisation, supervisor, and work group: Antecedents and outcomes. Journal of Vocational Behavior, 64(1), 47-71. https://doi.org/10.1016/S00018791(03)00029-0

Walters, E. (2008). Intentions to leave the workplace: The role of unfulfilled promises (unpublished master's dissertation). North-West University, Potchefstroom.

Weiss, D.J., England, G.W., \& Lofquist, L.H. (1967). Manual for the Minnesoto satisfaction questionnaire (Minnesota studies in vocational rehabilitation, No. 22). Minneapolis, MN: University of Minnesota Press.

Wieland, A.J. (2004). Business leadership and diversity: The relationships between team diversity climate, leaders' diversity attitudes, and leadership styles. Unpublished doctoral dissertation. The University of lowa.

Yalabik, ZY, Popaitoon, P., Chowne, J.A., \& Rayton, B.A. (2013). Work engagement as a mediator between employee attitudes and outcomes. The International Journal of Human Resource Management, 24(14), 2799-2823. https://doi.org/10.1080/0 9585192.2013 .763844

Zhao, X., Lynch, J.G., \& Chen, Q. (2010). Reconsidering Barron and Kenny: Myths and truths about mediation analysis. Journal of Consumer Research, 37(2), 197-206. https://doi.org/10.1086/651257 